\title{
Eyelids, eyelashes detection algorithm and houghtransform method for noise removal in iris recognition
}

\author{
Bounegta Nadia, Bassou Abdessalam, Beladgham Mohamed \\ Department of Electrical Engineering, University of Tahri Mohamed-Bechar, Algeria
}

\begin{tabular}{l} 
Article Info \\
\hline Article history: \\
Received Jul 25, 2019 \\
Revised Nov 26, 2019 \\
Accepted Dec10, 2019 \\
\hline
\end{tabular}

Keywords:

Biometric

Eyelash

Eyelid

Houghtransform

Iris recognition

\begin{abstract}
The biometric system is based on human's behavioral and physical characteristics. Among all of these, iris has unique structure, higher accuracy and it can remain stable over a person's life. Iris recognition is the method by which system recognize a person by their unique identical feature found in the iris. Iris recognition technology includes four subsections as, capturing of the iris image, segmentation, extraction of the needed features and matching. This paper is a detail description of eyelids; eyelashes detection technique and Hough transform method applied on iris image.
\end{abstract}

Copyright $@ 2020$ Institute of Advanced Engineering and Science. All rights reserved.

\section{Corresponding Author:}

Bounegta Nadia,

Department of Electrical Engineering,

University of Tahri Mohamed-Bechar,

P.B 417 Road of Kenadsa-Bechar, Algeria.

Email: bounegtanadia@gmail.com

\section{INTRODUCTION}

In recent years, the technology which is based on biometric identification got an instant development. Due to its high reliability, noncontact and some other advantages, iris recognition technology has widely acceptable [1-9]. Iris recognition is a method of biometric authentication, based on extracted features of the iris of an individual's eyes [1-3]. Every individual has its unique and stable iris features [11] Iris recognition technology is based on unique pattern which is found in human eye [12-14]. Iris recognition system is the fastest system as compare to the other biometric recognition system. It is having number of different characteristics. Iris recognition system can be used for recognition purpose. The different parts of the eye as shown in Figure 1.

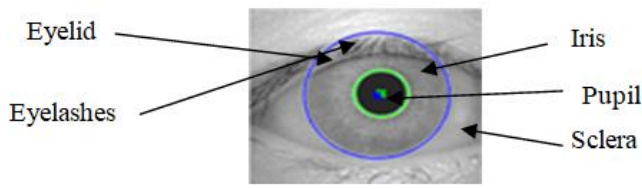

Figure 1.The different parts of the eye

\section{RESEARCH METHOD}

Idea of the iris recognition system is very old and it is firstly proposed by Frank. Among the all algorithms, most wellknown algorithm is proposed by Daughman $[2,15-16]$. He has produced improved 
result. M. Monro et al has proposed eyelashes removal method for human iris recognition [13]. Criteria based eyelashes detection model for IrisSegmentation is proposed by Wai-Kin Kong et al [15]. B. Kang et al proposed method of robust eyelashes detection based on iris focus assessment [9]. Many researchers also concentrate on the accuracy of the iris recognition system [2, 10, 13, 17-18]. Also many of them focused on the iris feature extraction and recognition systems. Noise factors affect the accuracy of the iris recognition system, so recently many researchers doing work on the noise removing techniques for iris image [2].

An Iris recognition system uses a small and high-quality gray scale camera to capture an image of the iris. Then we segment and normalize the iris image. After that, we use eyelashes detection algorithm to detect the eyelids and eyelashes in this iris image. Eyelids and eyelashes are the noise factors in the iris image. And we must have to remove these noise factors from the iris image to ensure an effective recongnition's rate. For this,canny edge detection technique can be used [17]. To detect the pupil and boundaries in the iris image, we can use Hough transform method. Hough transforms method works on the basis of parametric equations [19-20]. Hough Transform method can find geometric shapes such as circles, or lines within an image [19]. In this case we use the circular transform. In Figure 2, iris recognition system is made up of number of subsystems. Our paper is based on the first two part of this system i.e. capturing of the iris image and pre-processing.

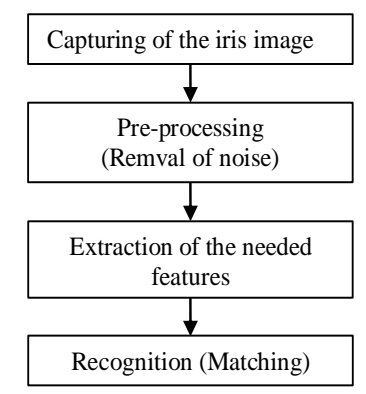

Figure 2. Iris recognition system block diagram

\subsection{Image Capturing}

The iris image can be taken by a gray-scale camera in specific distance from the camera $[1,17,21-22]$. When eye is properly stable then, iris image can be taken from this camera. This camera captures number of images and these images can be used for further use. We used CASIA Ver.01 iris database for this purpose. Numbers of images are available in the CASIA Ver.01 iris database. We have taken number of these iris images for recognition purpose.

\subsection{Pre-Processing}

Iris image is captured from camera [18]. This iris image may have some amount of noise [23-24]. This noise can be eyelids, eyelashes, masked regions etc. These noise factors affect the accuracy and speed of the iris recognition system [25]. Due to this noise, performance of the iris recognition system gets reduced. So, we have to remove these noise factors from the iris image. Preprocessing step helps us to remove iris image noise. Though performance of the system depends on this step, it plays important role in the iris recognition system. To remove these noise factors, we have used eyelids, eyelashes detection algorithm and circular, linear Hough transforms on the iris image.

\subsection{Feature Extraction}

This is also a very important step in iris recognition. This step can be used to get needed features of the iris image. Due to the memory problems, we need more small size iris data. In this step, needed features in the iris input image is chosen. These features can be used for further processing in matching step. With the help of these features, we can match one iris image with other iris image.

\subsection{Recognition}

Unique iris pattern is already stored in the iris pattern database. In this section, new iris pattern of the same individual is taken and matching of the already stored iris pattern and new iris pattern is takes place with the help of matching algorithm. We have not concentrated on this part in our paper. 


\section{RESULTS AND ANALYSIS}

\subsection{Eyelids and Eyelashes Detection Algorithm}

Eyelids and eyelashes are the noise factors in the iris image. And we must have to remove these noise factors from the iris image. To remove these eyelids and eyelashes from iris image we can use eyelids and eyelashes detection algorithm. This algorithm runs in six stages as follows:

For the upper eyelids,

Ex:

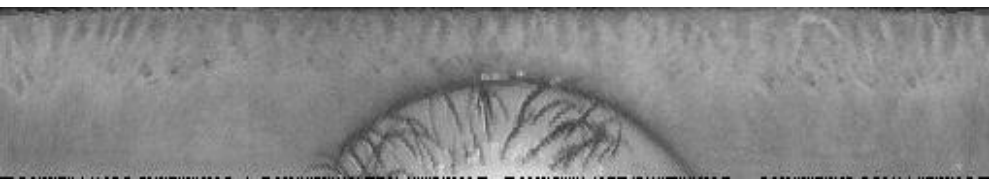

1/ Histogram equalization:

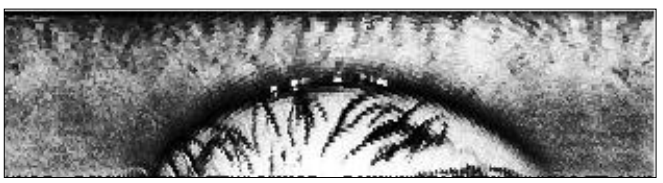

2/ Using a scale (see [13])

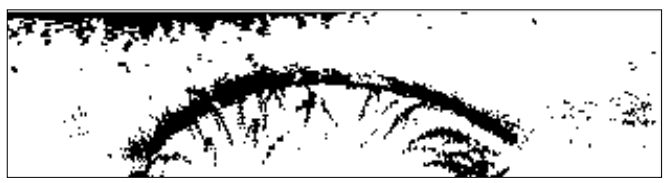

3/ Complement of the image

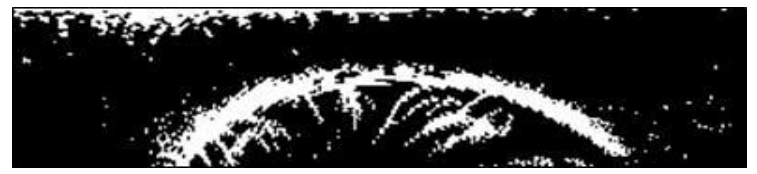

4/ Eliminate noise greater than 50 pixels

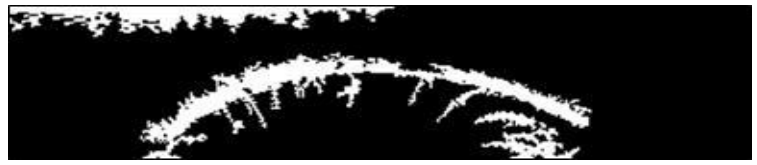

5/ Add the right and left areas

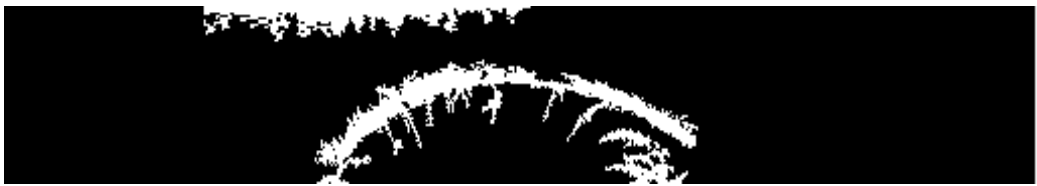

6/ Apply the circular Hough transform

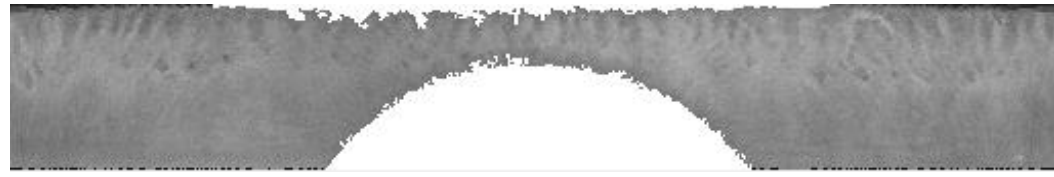

We repeat these steps for the lefts and rights eyelids,

Ex:

Eyelids, eyelashes detection algorithm and houghtransform method for noise removal in... (Bounegta Nadia) 

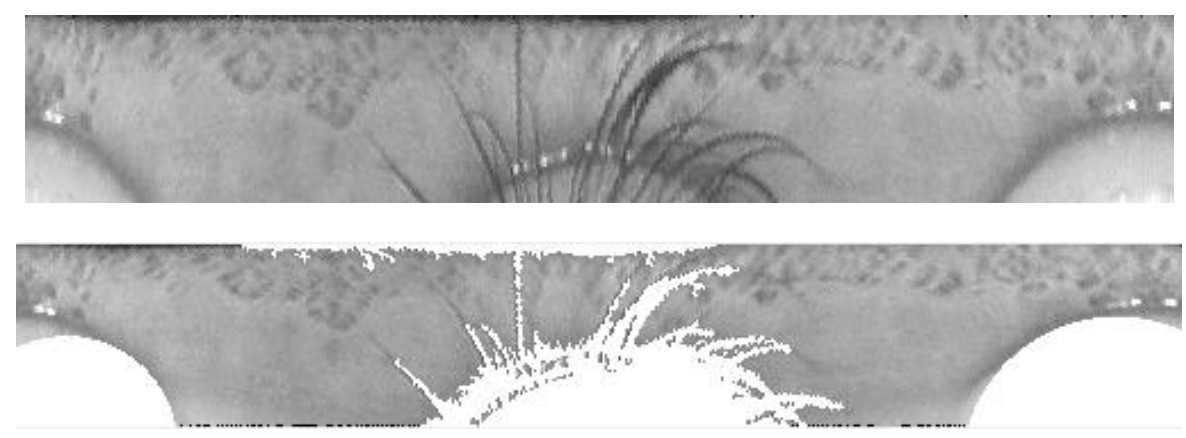

According to these results the recognition's rate is: $99.99 \%$

\section{CONCLUSION}

A new eyelid and eyelashes detection method is discussed with reduced noise. Eyelids and eyelashes detection method is more accurate. This system will reduce the time for detecting the eyelids and eyelashes of the iris image with the help of circular Hough transform.

\section{REFERENCES}

[1] Yulin Si, Jiangyuan Mei, and HuijunGao, February 2012,'Novel Approches to Improve Robustness, Accuracy and Rapidity of Iris Recognition System", IEEE Transactions On Industrial Informatics, VOL. 8, NO. 1, PP. 110-117.

[2] Hui Li, Suyan Zhang, Zhanzhan Zhang,"Research on Iris Recognition Method Based on Quantum Algorithms ", TELKOMNIKA Indonesian Journal of Electrical Engineering Vol. 12, No. 9, September 2014, pp. $6846 \sim 6851$, DOI: 10.11591/telkomnika.v12i9.5081.

[3] Hazim G. Daway, Hana H. kareem, Ahmed Rafid Hashim," Pupil Detection Based on Color Difference and Circular Hough Transform", International Journal of Electrical and Computer Engineering (IJECE) Vol. 8, No. 5, October 2018, pp. 3278 3284; ISSN: 2088-8708, DOI: 10.11591/ijece.v8i5.pp3278-3284.

[4] Gopalakrishna K, Hariprasad S. A," Real-Time Fatigue Analysis of Driver through Iris Recognition, International Journal of Electrical and Computer Engineering (IJECE) Vol. 7, No. 6, December 2017, pp. 3306 3312 ISSN: 088-8708, DOI: 10.11591/ijece.v7i6.pp3306-3312.

[5] Mrunal Pathak, N. Srinivasu, Vinayak Bairagi," Effective segmentation of sclera, iris and pupii in noisy eye images", TELKOMNIKA, Vol.17, No.5, October 2019, pp.2346 2354 ISSN: 1693-6930, accredited First Grade by Kemenristekdikti, Decree No: 21/E/KPT/2018,DOI: 10.12928/TELKOMNIKA.v17i5.12551.

[6] Narongrit Wangkeeree, Sirapat Boonkrong," Finding a suitable threshold value for an iris-based authentication system", International Journal of Electrical and Computer Engineering (IJECE) Vol. 9, No. 5, October 2019, pp 3558 3568,ISSN: 2088-8708, DOI: 10.11591/ijece.v9i5.pp3558-3568.

[7] Kamel Ghanem Ghalem1, Fatiha Hendel,"Dual iris authentication system using desert smarandache theory", International Journal of Electrical and Computer Engineering (IJECE) Vol. 9, No. 6, December 2019, pp. 4703 4712,ISSN: 2088-8708, DOI: 10.11591/ijece.v9i6.pp4703-4712.

[8] Priti S. Sanjekar, J. B. Patil ," Multimodal biometrics with serial, parallel and hierarchical mode at decision level fusion, Indonesian Journal of Electrical Engineering and Computer Science Vol. 16, No. 3, December 2019, pp. 1303 1310 ISSN: 2502-4752, DOI: 10.11591/ijeecs.v16.i3.pp1303-1310 .

[9] Thulfiqar H. Mandeel, Muhammad Imran Ahmad, Said Amirul Anwar," A multi-instance multi-sample palmprint identification system", Indonesian Journal of Electrical Engineering and Computer Science Vol. 13, No. 2, February 2019, pp. 825 830 ISSN: 2502-4752, DOI: 10.11591/ijeecs.v13.i2.pp825-830.

[10] Dangui Chen, Guojun Qin," An Embedded Iris Image Acquisition Research", Indonesian Journal of Electrical Engineering and Computer Science Vol. 5, No. 1, January 2017, pp. 90 9,DOI: 10.11591/ijeecs.v5.i1.pp 90-98.

[11] C.M.Patil, SudarshanPatilkulkarani, 2009, "An Approach of Iris Feature Extraction for Personal identification", International Conference on Advances in Recent Technologies in Communication and Computing, IEEE, PP. 796-799.

[12] D. Zhang, D. M. Monro and S. Rakshit, July 2001, "Eyelashes Removal Method For Human Iris Recognition", Department of Electronic and Electrical Engineering, University of Bath, PP. 1-4.

[13] John Daugman, 2009, "Iris Recognition for Personal Identification", The Computer Laboratory, University of Cambridge. http://www.cl.cam.ac.uk/users/jgd1000/iris_recognition.html.

[14] Zhaofeng He, Tieniu Tan, Fellow, IEEE, Zhenan Sun, Member, IEEE, and XianchaoQiu, 2008, "Towards Accurate And Fast Iris Segmentation For Iris Biometrics", IEEE Transactions On Pattern Analysis And Machine Intelligence, PP. 1-14.

[15] Lee Laun Ling, Daniel Felix de Brito, April 2010 "Fast \& Efficient Iris Image Segmentation”, Journal On Medical And Biological Engineering, PP. 381-392.

[16] Wai-Kin Kong, David Zhang, "Criteria Based Eyelashes Detection Model For Accurate Iris Segmentation", The Hong Kong Polytechnic University, Hong Kong, PP. 1-12. 
[17] https://github.com/chandravadans/IrisRecognition

[18] Ya-Ping Huang, Si-Wei Luo, En-Yi Chen, 4-5 November 2002, "An Efficient Iris Recognition System", Proceedings of the First International Conference on Machine Learning and Cybernetics, Beijing, PP. 450-454.

[19] Vineet Kumar, Abhijit Asati, Anu Gupta, "Accurate Iris Localization Using Edge Map Generation and Adaptive Circular Hough Transform for Less Constrained Iris Images", International Journal of Electrical and Computer Engineering (IJECE), Vol. 6, No. 4, August 2016, pp. 1637 1646 ISSN: 2088-8708, DOI: 10.11591/ijece.v6i4.9756

[20] Rubel Biswas, Jia Uddin, Md. Junayed Hasan, "A New Approach of Iris Detection and Recognition", International Journal of Electrical and Computer Engineering (IJECE), Vol. 7, No. 5, October 2017, pp. 2530-2536 ISSN: 2088-8708, DOI: 10.11591/ijece.v7i5.pp2530-2536.

[21] John Canny, "A computational approach to edge detection. Pattern Analysis and Machine Intelligence", IEEE Transactions on, PAMI-8(6):679-698, Nov. 1986.

[22] Sofea Ramli, Sharifalillah Nordin, "Personality Prediction Based on Iris Position Classification Using Support Vector Machines", Indonesian Journal of Electrical Engineering and Computer Science(IJEECS), Vol. 9, No. 3, March 2018, pp. 667-672 ISSN: 2502-4752, DOI: 10.11591/ijeecs.v9.i3.pp667-672

[23] Hsiau Wen Lin, Hwei Jen Lin, Yue Sheng Li," An Effective Iris Recognition System", TELKOMNIKA Indonesian Journal of Electrical Engineering,Vol.12, No.5, May 2014, pp. 3399-3406, DOI: http://dx.doi.org/10.11591/telkomnika.v12i5.4951

[24] Salah H Refish, Zaid Ameen Abdul jabbar, Zaid Alaa Hussien,Thair A Kadhim, Ali A Yassin, Mohammed Abdulridha Hussain, Salam Waley," Ensuring Data Integrity Scheme Based on Digital Signature and Iris Features in Cloud".

[25] Maulisa Oktiana, Fitri Arnia, Yuwaldi Away, Khairul Munadi, "Features for Cross Spectral Image Matching: A Survey", Bulletin of Electrical Engineering and Informatics(BEEI), Vol. 7, No. 4, December 2018, pp. 552-560, ISSN: 2302-9285, DOI: 10.11591/eei.v7i4.843 